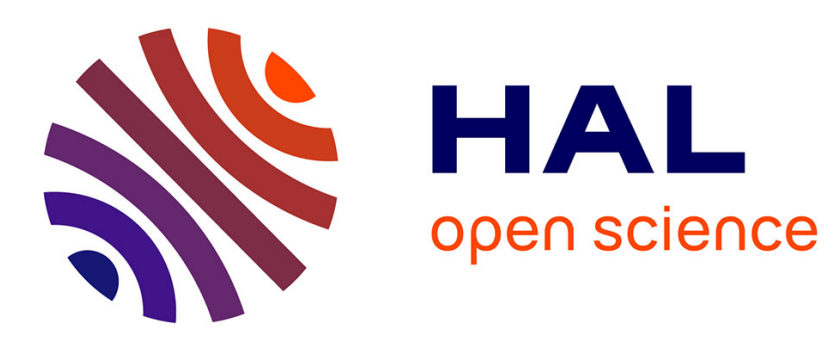

\title{
Fungal communities are more sensitive indicators to non-extreme soil moisture variations than bacterial communities
}

\author{
A. Kaisermann, P.A. Maron, L. Beaumelle, J.C. Lata
}

\section{- To cite this version:}

A. Kaisermann, P.A. Maron, L. Beaumelle, J.C. Lata. Fungal communities are more sensitive indicators to non-extreme soil moisture variations than bacterial communities. Applied Soil Ecology, 2015, 86, pp.158-164. 10.1016/j.apsoil.2014.10.009 . hal-01079760

\section{HAL Id: hal-01079760 \\ https://hal.sorbonne-universite.fr/hal-01079760}

Submitted on 3 Nov 2014

HAL is a multi-disciplinary open access archive for the deposit and dissemination of scientific research documents, whether they are published or not. The documents may come from teaching and research institutions in France or abroad, or from public or private research centers.
L'archive ouverte pluridisciplinaire HAL, est destinée au dépôt et à la diffusion de documents scientifiques de niveau recherche, publiés ou non, émanant des établissements d'enseignement et de recherche français ou étrangers, des laboratoires publics ou privés. 
1 Fungal communities are more sensitive indicators to non-extreme soil moisture variations than bacterial communities

3

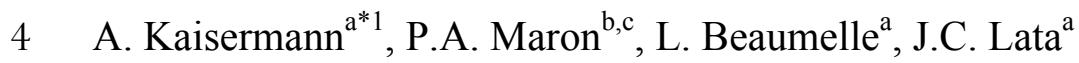

5

6 a Sorbonne Universités, UPMC Univ Paris 06, UMR 7618, Institut $i$ EES $_{\text {Paris, École Normale }}$

7 Supérieure, 46 rue d'Ulm, 75230 Paris Cedex 05, France

8

$9 \quad{ }^{\mathrm{b}}$ INRA, UMR 1347 Agroecology, Dijon, France

$10{ }^{\mathrm{c}}$ INRA, Plateforme GenoSol, UMR1347 Agroecology, Dijon, France

$11{ }^{1}$ Present address: Michael smith Building, Faculty of Life Sciences, The University of

12 Manchester, Oxford Road, Manchester M13-9PT, United Kingdom

$14{ }^{*}$ Corresponding author: Tel: + 441612751484

15 Aurore Kaisermann: Aurore.kaisermann@manchester.ac.uk

16 Pierre-Alain Maron: pamaron@dijon.inra.fr

17 Léa Beaumelle: Lea.Beaumelle@versailles.inra.fr

18 Jean-Christophe Lata: lata@biologie.ens.fr

19 


\section{Abstract}

21 Many studies have focused on the impact of intense drought and rain events on soil

22 functioning and diversity, but little attention has been paid to the response of microbial

23 communities to non-extreme soil moisture variations. However, small fluctuations of soil

24 water content represent a common situation that ought to be examined before understanding

25 and deciphering the impact of extreme events. Here, we tested the impact of a decrease in

26 average soil water content and small water content fluctuations in non-extreme conditions on

27 microbial community composition and $\mathrm{C}$ mineralisation rate of a temperate meadow soil.

28 Two soil microcosm sets were incubated at high and low constant moisture and a third set

29 was subjected to 4 short dry-wet cycles between these two soil moistures. No robust change

30 in bacterial community composition, molecular microbial biomass, and fungal:bacterial ratio

31 were associated with soil water content change. On the contrary, the fungal community

32 composition rapidly alternated between states corresponding to the high and low levels of soil

33 moisture content. In addition, gross $\mathrm{C}$ mineralisation was correlated with soil moisture, with a

34 noteworthy absence of a Birch effect ( $\mathrm{C}$ over-mineralisation) during the wetting. This study

35 suggests that some fungal populations could coexist by occupying different moisture niches,

36 and high fungal community plasticity would classify them as more sensitive indicators of soil

37 moisture than bacteria. Moreover, under non-stressed conditions, the community composition

38 did not affect metabolic performance so a future decrease in average soil moisture content

39 should not result in a supplemental loss in soil carbon stocks by a Birch effect.

\section{Keywords}

42 Soil moisture fluctuation; ARISA fingerprinting method; C mineralisation; metabolic 43 activity; pore size; moisture niche. 
Microbial community structure could play a role in the ability of communities to realize different functions but also to resist environmental disturbance (Torsvik and Øvreås, 2002). In the context of global change, microbial community structure could be modified and therefore impact ecosystem functioning. Soil moisture is one of the major factors influencing microbial community structure (Brockett et al., 2012) and the shift of microbial community structure is suspected to contribute to important pulses in net mineralisation during the rewetting of dry soils (Borken and Matzner, 2009). But where some authors have suggested that periods of soil water restriction and wetting of dry soil affect microbial community structure through induced osmotic stress and resource competition occasioning selective pressure (Fierer et al., 2003; Castro et al., 2010), others reported no change in microbial community structure (Griffiths et al., 2003).

These contradictory findings in the literature may be due to the specificity of studied ecosystems but also to differences in experimental approaches (Borken and Matzner, 2009).

60 On one hand, the assumed change of the microbial community structure is often made from 61 circumstantial evidence (e.g. changes in biomass or activity). On the other hand, the effects

62 of drying and wetting are frequently not distinguished, and "drying soil" and "drought" often

63 merged. Climatic models forecast a decrease of average soil moisture and an intensification

64 of extreme events (IPCC, 2007), but it is still uncertain to what extent the soil system can

65 become unbalanced under these perturbations. While many studies have focused on intense

66 water-stress, little attention has been paid to the response of microbial communities in non-

67 extreme conditions to characterise their stability to natural variability (Meier et al., 2008).

68 However, small fluctuations of soil water content in non-extreme conditions represent a 
69 common situation that needs to be explored before understanding and deciphering the impact

70 of extreme events.

A limited decrease in soil moisture may be a stressful process for some microorganisms, due to physical constraints that affect bacterial or fungal habitats (Or et al., 2007). At the scale of soil aggregates, the basic units of microbial habitats, drying is heterogeneous and can induce a localized drought that stresses microorganisms; particularly in larger pores (Ruamps et al., 2011). Besides, the decrease of pore connectivity could also modify the microbial community structure by decreasing bacterial mobility and the rate of substrate diffusion (Carson et al., 2010). Fungal communities, on the other hand, are thought to be better adapted to drying than bacteria thanks to hyphal networks which facilitate access to water and nutrients. The question therefore arises as to how fluctuating water content without total drought influences microbial community structure and if the sensitivity of bacterial and fungal community is the same. Beyond the fact that it is still unclear whether a microbial community is associated with a given soil water content, it could be unaltered or alternate between states reflecting the different levels of soil moisture, but also experience another state, reflecting a transient community associated with drying or wetting or both. The objectives of this study were to examine in non-extreme moisture conditions: (i) whether the composition of bacterial and fungal communities is similar at two contrasting water contents; (ii) how the microbial community composition responds to water content fluctuation within a narrow range of soil moisture; and (iii) whether the microbial community composition can contribute to explain soil functioning. We performed a microcosm experiment consisting of two sets of microcosms kept steadily wet at $64 \%$ and $33 \%$ WaterHolding Capacity (WHC), respectively. A third set was subjected to 4 dry-wet cycles over a one-month period and subsequently kept steadily at $64 \%$ WHC for 4 additional months. At 
94 molecular tools (crude DNA quantity for molecular microbial biomass, A-RISA

95 fingerprinting method for structure and $\mathrm{qPCR}$ for abundance), and $\mathrm{C}$ mineralisation rate was 96 measured through $\mathrm{CO}_{2}$ quantification.

97

98

99

\section{Materials and methods}

\subsection{Site description and soil characteristics}

Soil was sampled from uncultivated meadow bordering cultural field at Versailles, France (mean annual precipitation: $630 \mathrm{~mm}$; mean annual temperature: $10.5^{\circ} \mathrm{C}$ ); which is an ecosystem with a high ecological importance in urban locations (Manninen et al., 2010). Vegetation (ruderal nitrophilous dominated by Trifolium repens) and soil properties of this site are representative of the northern region of France. Fourteen random samples of one kilogram were collected from the topsoil (0-6 cm depth) in August 2010 then combined and homogenized in order to obtain one unique microbial community representative of this ecosystem by lessening spatial heterogeneity. The soil was air-dried, sieved to $4 \mathrm{~mm}$, and vegetation debris, rocks and any fauna visible to the naked-eye were removed before use. The soil is classified as a silty loam (Eutric Cambisol, WRB) with $148 \mathrm{~g} \cdot \mathrm{kg}^{-1}$ of clay, $347 \mathrm{~g} . \mathrm{kg}^{-1}$ of silt and 496 g.kg-1 of sand. Characterised according to standard methods (http://www.lille.inra.fr/las/methodes_d_analyse/sols), the $\mathrm{pH}_{\mathrm{H}_{2} \mathrm{O}}$ was 6, and there was 20.6 g. $\mathrm{kg}^{-1}$ of organic $\mathrm{C}$, less than $1 \mathrm{~g} . \mathrm{kg}^{-1}$ of $\mathrm{CaCO}_{3}, 1.6 \mathrm{~g} . \mathrm{kg}^{-1}$ of total $\mathrm{N}$ hence a $\mathrm{C} / \mathrm{N}$ of 12.6. Water-holding capacity (WHC) was of $0.41 \mathrm{~g}$ of water per $\mathrm{g}$ of dry soil.

\subsection{Experimental design}

Microcosms, consisting of $40 \mathrm{~g}$ dry soil equivalent in $126 \mathrm{~mL}$ glass bottles, were preincubated for 6 weeks at $18.5^{\circ} \mathrm{C}$ in the dark at desired moisture in order to stabilize the soil microbial communities. Microcosms of high moisture treatment (HM) were maintained at 
$11964 \%$ WHC $(\mathrm{pF}=2.24)$, corresponding to the maximum expected microbial activity, and

120 microcosms of low moisture treatment $(\mathrm{LM})$ at $33 \% \mathrm{WHC}(\mathrm{pF}=3.67)$ by sealing them with

121 parafilm $^{\circledR}$. Fluctuating moisture treatment (FM) consisted of 4 cycles of air-drying for one 122 week from $64 \%$ WHC until about 33\% WHC then wetting to $64 \%$ WHC by addition of

123 sterile Milli-Q water. As moisture levels were monitored gravimetrically throughout the 124 incubation (Fig. 3a), the quantity of added water balanced the quantity of water lost during 125 the drying. Time 0 is the first day of the first drying period, and the rewetting events for FM 126 were at 7, 14, 21 and 28 days. After these four cycles, microcosms were subsequently sealed 127 and incubated for a further 4 months at $64 \%$ WHC. Three replicate microcosms per FM 128 treatment were destructively sampled at the end of drying period ("Fluctuating Moisture" at 129 low moisture, FM-1) and two days after wetting ("Fluctuating Moisture" at high moisture, 130 FM-h) for the four cycles, then at 60,90 and 145 days at constant moisture, resulting in $\mathrm{n}=$

13133 FM microcosms. Constantly moist microcosms (HM and LM) were sampled in triplicate 132 at $0,14,28,60,90$ and 145 days, resulting in $\mathrm{n}=18$ microcosms per treatment. Soil samples 133 were stored at $-20^{\circ} \mathrm{C}$ until required for microbial analyses.

\section{2.3. DNA extraction: molecular microbial biomass} Total soil DNA was extracted and purified following the GnS-GII procedure, as described in Terrat et al. (2012). The DNA concentration of crude extracts was calculated using a calf thymus standard curve. This soil DNA concentration can be used as a robust

138 indicator of soil microbial biomass (Marstorp et al., 2000) defined by Dequiedt et al. (2011)

139 as the molecular microbial biomass. Crude DNA extracts were purified using PVPP 140 minicolumns (BIORAD, Marne La Coquette, France) and Geneclean Turbo Kit (Q

141 Biogene ${ }^{\circledR}$, Illkirch, France) following the manufacturer's instructions.

\section{2.4. Quantitative PCR: microbial density}


144 PCR using two pairs of universal primers to estimate bacterial (Primer Gold 341F/515R;

145 López-Gutiérrez et al., 2004) and fungal abundances (FR1/FF390; Vainio and Hantula, 2000)

146 following the procedure described in Chemidlin Prévost-Bouré et al. (2011).

147 2.5. ARISA fingerprinting: genetic structure of microbial community

148 Automated Ribosomal Intergenic Spacer Analysis (ARISA), a molecular

149 fingerprinting method (Ranjard et al., 2001), has been used to characterise the genetic

150 structure of bacterial (B-ARISA) and fungal (F-ARISA) communities for all samples except

151 the third dry-wet cycle. ARISA was used since it has been demonstrated to be a high-

152 resolution, robust and highly reproducible technique for evaluating microbial communities

153 change through space and time (Ranjard et al., 2001; Jones et al., 2007). The bacterial

154 ribosomal intergenic spacer region (IGS) and the fungal internal transcribe spacer (ITS) were amplified by PCR using primers S-D-Bact-1522-b-S-20/L-D-Bact-132-a-A-18 and ITS1F/3126T, respectively. Purified PCR products were added to deionized formamide and

157 fragments were resolved on polyacrylamide gels under denaturing conditions as described by

158 Pascault et al. (2010) on a LiCor ${ }^{\circledR}$ sequencer (ScienceTec, France).

\subsection{C mineralisation rate}

$\mathrm{C}$ mineralisation was measured as the daily $\mathrm{CO}_{2}$ gas flux on three replicate

161 microcosms per treatment, the day before the wetting, one hour after the wetting as well as

162 the two consecutive days, then once a week the second month, and finally monthly until the

163 end of incubation. Measurements were carried out using a micro-gas chromatograph as 164 described in Kaisermann et al. (2013).

\subsection{Statistical analysis}

All statistical analyses were performed using the R software v. 2.13 (R Development

167 Core Team, 2011). The ARISA data were analysed using Non-metric multidimensional 
168 scaling (NMDS) implemented in Vegan package (Oksanen et al., 2008) with Bray-Curtis

169 distance measure to generate the dissimilarity matrices. Optimal MDS configurations were

170 determined using 1000 random starts and the lowest stress values were used. The sample

171 discrimination according to treatment, time, and the interaction was tested through a non-

172 parametric manova using the Adonis function (Vegan package; Oksanen et al., 2008) on

173 Bray-Curtis dissimilarity matrices with 999 permutations. This method partitions distance

174 matrices among sources of variations and uses a permutation test with pseudo-F ratios. A first

175 NMDS (Fig. 1a and Fig. 2a) was performed with all samples with the Adonis analysis

176 including 3 treatments (HM, LM, FM) and 7 sampling times. A second NMDS (Fig. $1 \mathrm{~b}$ and

177 Fig. 2b) was performed for the first month in order to analyse separately the effect of

178 moisture variation in FM treatment with the Adonis analysis including 4 treatments (HM,

179 LM, FM-h, FM-1) and 4 sampling times. Confidence ellipses at 95\% were included in

180 ordinations to examine the variability of samples over "time" in the first NMDS, and for

181 "treatment effect" in the second NMDS. Moreover, when the treatment effect was significant,

182 treatments have been compared in a pairwise fashion with independent Adonis tests in order

183 to detail which treatments were different from the others. As the experimental design has

184 nestedness (time effect), we also specified "strata $=$ time" in the Adonis test so that

185 randomization occurs only within each time point.

186 The differences between treatments for molecular microbial biomasses and 18S:16S

187 ratios were analysed with a linear mixed effect model using the lme function implemented in

188 the nmle package (http://lme4.r-forge.r-project.org/) where 'time' was included as a random

189 effect. Significant differences $(\mathrm{P}<0.05)$ were evaluated by ANOVA.

190 For C mineralisation rates, the dependence of the measurement through time on the

191 same microcosms was integrated with "microcosm ID" as a random effect in the lme. When

192 C mineralisation is expressed by $\mathrm{g}$ water.g soil ${ }^{-1}$, the two constantly wet treatments (LM and 
193 HM) presented no difference throughout the incubation: the mineralisation rate decreased

194 linearly as a function of time, and the equations describing the relationship in both treatments

195 were not significantly different (treatment effect $P=0.46$, treatment*time effect $P=0.14$;

196 Supplemental data, Fig. S1). Therefore, we used data from LM and HM treatments to

197 determine if the variations of moisture in FM treatment induced a supplemental modification

198 of soil respiration than the one expected due to the only modification of water content. The 199 expected mineralisation rate for LM treatment for a given moisture at a given time was 200 calculated as: Cexpected $=(-0.0043 T+0.9307) \times W c$; where Cexpected is the expected $\mathrm{C}$ 201 mineralisation rate in $\mu \mathrm{g} \mathrm{C}-\mathrm{CO}_{2} \cdot$ gsoil $^{-1}$.days ${ }^{-1}, T$ the time in days and $W c$ the water content in 202 gwater.gsoil ${ }^{-1}$. To estimate the effect of drying and wetting on $\mathrm{C}$ mineralisation, the observed 203 value of FM was compared to the expected value using lme with treatment and time as fixed 204 effects and the significance estimated by ANOVA.

\section{Results}

\subsection{Genetic structure of bacterial communities}

The non-metric multidimensional scale analysis of all B-ARISA profiles showed changes in bacterial community structure over time but without difference between the different treatments (Fig. 1a). The data taken from the first month (Fig. 1b) confirmed the

211 similarity of the bacterial communities between the constant moisture treatments $(\mathrm{HM}=\mathrm{LM})$

212 (Table 1), between high moisture treatments $(\mathrm{HM}=\mathrm{FM}-\mathrm{h})$ and between low moisture 213 treatments $(\mathrm{LM}=\mathrm{FM}-1)$. However, the FM treatment after the drying periods (FM-1) was 214 significantly different from the high moisture treatments (HM and FM-h). Therefore, 215 bacterial community composition was identical between the different water contents but a 216 part of the community was different at the end of drying period.

\section{3.2. Genetic structure of fungal communities}


219 strong time effect on fungal community structures, especially for days 60 and 145 and also a

220 treatment effect (Fig. 2a). The pairwise comparison showed that fluctuating moisture 221 treatment (FM) was similar to high and low moisture treatments $(P=0.171$ for $\mathrm{HM}$ and

$222 P=0.126$ for LM, respectively) when HM and LM fungal communities were significantly 223 different $(P=0.014)$.

224 The data taken from the first month (Fig. 2b) revealed significant differences between 225 all treatments expect for the fungal communities of LM and FM-1 (Table 1). The statistical 226 difference between HM and FM-h was not confirmed by visual observations of NMDS for 227 times 0 and 14 and actually can only be explained by the high variability of replicates at the 228 time 28 (and corroborated by the strong Time*Treatment effect $(P=0.005)$ when the test is 229 done without strata). Therefore, fungal community structure was different between HM and 230 LM, and alternated in the FM treatment between states corresponding to the high and low 231 levels of soil moisture content.

\section{3.3. Microbial molecular biomass, abundance and activity}

233 Molecular microbial biomass (Fig. 3b) and fungi:bacteria ratio measured as 18S:16S 234 ratio (Fig. 3c) were similar between all treatments ( $P=0.07$ and $P=0.63$, respectively). The $\mathrm{C}$ 235 mineralisation rate of the HM treatment was higher than the LM treatment (Fig. 3d), but was 236 similar when expressed by g water ${ }^{-1}$ (Supplemental data S1). The C mineralisation rate of FM 237 fluctuated between the C mineralisation rates of the HM and LM treatments ("time effect" $238 P<0.0001)$. More precisely, the $\mathrm{C}$ mineralisation rates decreased when the soil dried, and 239 became similar to the HM treatment after the wetting. There was no difference between 240 observed values of FM and expected values $(P=0.46)$ at all incubation times ("Treatment $\mathrm{x}$ 241 time effect" $P=0.14$ ), showing that moisture variations in FM treatment did not induce a 
supplemental modification of soil respiration (i.e. over-mineralisation) than the one expected due to the modification of water content.

bacterial community compositions were similar whereas the fungal community compositions were distinct. Therefore, only the fungal community presents a specific composition depending on soil moisture. This may reflect the difference of ecological habitat between these two guilds (Chenu et al., 2001). Indeed, fungi could preferentially live in large pores, which are filled at high moisture but empty at low moisture; bacteria in turn would live in smaller pores, better protected against these perturbations. In order to discuss ecological patterns, the overall communities can be examined in terms of populations, or subsets of communities. Therefore, the relative abundance of fungal populations inhabiting the large pores could be decreased in dry conditions while the abundance of other populations could increase at the new air-water interface, which explains the dissimilarity of fungal communities between these two moisture levels. Contrastingly, the lack of difference for the bacterial community is unexpected as different pore or aggregate size classes support distinct bacterial populations (Ruamps et al., 2011; Davinic et al., 2012). This could indicate that bacteria either only inhabit the smallest pores still filled with water at low moisture content, or bacterial populations inhabiting large pores are not impacted when pores are empty at low moisture. The latter could be the result of either (i) the presence of sufficient water on pore walls to ensure favourable living conditions or (ii) that bacterial populations themselves maintain a favourable habitat compliments of their lifestyle strategy, since a lot of soil bacteria are able to live in biofilms, embedded in extracellular polymeric substances (Or et al., 2007). 
While constant levels of moisture resulted in unchanged bacterial communities,

268 fluctuations resulted in a small modification of the bacterial community structure during the

269 first month. This may result from population shifts within a small portion of the overall

270 community. Indeed, at the aggregate scale, the drainage of pores may be heterogeneous, and

271 since bacteria are dependent on the water in their immediate vicinity, the bacterial

272 community could be only partially in stressful conditions. A finer estimation of how the

273 dynamics of bacterial populations localized in different microenvironments are affected by

274 water fluctuation (i.e. different aggregate size or preferential flow paths; Bundt et al., 2001) is

275 necessary to determine whether a transient community is associated with drying periods.

276 Nevertheless, for the whole of the bacterial community, the community similarity when the

277 water content is half and the lack of large and permanent changes during the water

278 fluctuation, reinforces the hypotheses that either the whole localised bacterial community is

279 adapted to this water disturbance (Griffiths et al., 2003; Meier et al., 2008) or there is no

280 water-stress at this range of soil moisture (Manzoni et al., 2012) at this scale of community

281 integration.

282 The water fluctuation induced a strong change in the fungal community structure that alternated between states reflecting the high and low levels of soil moisture. This transient response suggests that all species could survive and coexist in this order of magnitude of moisture but that different fungal populations within the community would dominate at different moisture levels. Therefore, notions of tolerance range and ecological optimum of Shelford's law are illustrated here for fungal communities (Shelford, 1931). Indeed, the success of an organism depends upon fulfilment of various conditions, the growth being optimal when all the factors are in optimal range. But if one factor, here the water, is deficient or in excess, the limits of survival of an organism are approached (deviation of ecological optimum) and so its growth is decreased. This is also consistent with Lennon et al. 
292 (2012) who suggested that some taxa may be able to coexist by partitioning the moisture 293 niche axis. When a moisture shift occurs, a reduction of the activity of dominant fungi 294 adapted to previous moisture content could result in a reduction in competitive ability against 295 other fungal taxa, which will then be able to dominate the community at the new water 296 content (Allison and Treseder, 2008). The rapid observed shift is quite surprising, but could 297 be explained by rapid hyphal turnover (Staddon et al., 2003; de Vries et al., 2009) and the 298 ability of some taxa to grow even in drying periods (Bapiri et al., 2010; Yuste et al., 2011). Therefore, the drought tolerance of fungal communities often claimed in studies could

300 be explained not only by facilitated nutrient access through hyphal networks, but also by a 301 rapid turnover of populations conferring high plasticity to the community. Moreover, the 302 higher variability within the fungal community composition compared to the bacterial community, already highlighted in field condition (Zumsteg et al., 2013), suggests that fungi might be more sensitive indicators of soil moisture than bacteria in non-extreme conditions. Additionally, since such stability of bacterial communities is not always observed after more intense droughts (Fierer et al., 2003; Castro et al., 2010), our study reinforces the concerns about the functioning and resilience of soils undergoing intense droughts because of a permanent impact on bacterial communities.

At this range of soil moisture, $\mathrm{C}$ mineralisation rates were positively correlated to soil water content. Two outcomes can be drawn from this result. First, it is worth noting the

311 absence of $\mathrm{C}$ over-mineralisation after the wetting, a phenomenon known as the 'Birch 312 effect', which is commonly observed in many ecosystems (Borken and Matzner, 2009). This suggests that rainfall without prior soil drought did not induce additional $\mathrm{C}$ loss, which

314 supports the findings of Fischer (2009), that a minimal water content must be reached before wetting to generate this flush. Secondly, as the molecular microbial biomass and abundance were similar between treatments, the soil respiration variations were probably due to changes 
317 in metabolic rates of the overall community. Indeed, it is well documented that when soil

318 water potential decreases, the metabolic activity of some microbial species is decreased

319 (Schimel et al., 2007; Manzoni et al., 2012). However, the activity expressed per gram of

320 water is similar at all the water contents, showing that where there is an activity, the activity

321 rate is preserved. With the assumption that the fungal populations that dominated at low

322 water content have an increased activity (or at least their relative contribution within

323 community activity), metabolic adjustments could occur within the overall community to

324 maintain the same metabolic rate. The lack of a link between composition changes and

325 metabolic activity supports the idea that functional redundancy maintains the metabolic rate

326 in non-extreme moisture conditions. Therefore our study suggests, as already presented by

327 Comte and Del Giorgio (2011) and Baltar et al. (2012) for aquatic ecosystems, that overall

328 metabolic performance of a soil microbial community is determined by environmental drivers

329 and can be achieved through different configurations of community composition.

330 In conclusion, this study illustrates that, taken as a whole and at this range of

331 moisture, (i) the fungal community composition depends on non-extreme moisture conditions

332 in contrast to the bacterial community possibly due to differences in niche preference, (ii) the

333 moisture fluctuation induces a rapid turnover of fungal populations conferring a high

334 community plasticity; therefore fungal community would be a more sensitive indicator of soil

335 moisture than bacteria, (iii) and the community metabolic performance is determined by

336 environmental drivers, the community showing functional redundancy in non-stressed

337 conditions. Finally, our study showed that a microbial community is adapted to cope with

338 non-extreme moisture variation. This reinforces the need to understand why some studies

339 have shown that microbial communities could be lastingly modified by severe drought and

340 evaluate their consequences on ecosystem functioning. For this purpose, it is essential to

341 estimate critical minimum moisture thresholds for microbial community shifts, and thus 
assess the effects of intensity and duration of drying and wetting events on the stability of microbial communities.

Acknowledgements: This work was funded by the Région Île-de-France via the R2DS

346 funding program and the Centre National pour la Recherche Scientifique (CNRS) via the

347 INSU- EC2CO funding program. The authors are grateful to two anonymous reviewers and want to thank E. Fry for suggestions and for improving the English of the original manuscript.

\section{References}

Allison, S.D., Treseder, K.K., 2008. Warming and drying suppress microbial activity and carbon cycling in boreal forest soils. Glob. Change Biol. 14, 2898-2909.

Baltar, F., Lindh, M.V., Parparov, A., Berman, T., Pinhassi, J., 2012. Prokaryotic community

Bapiri, A., Bååth, E., Rousk, J., 2010. Drying-rewetting cycles affect fungal and bacterial structure and respiration during long-term incubations. MicrobiologyOpen 1, 214-224.

Borken, W., Matzner, E., 2009. Reappraisal of drying and wetting effects on $\mathrm{C}$ and $\mathrm{N}$ mineralization and fluxes in soils. Glob. Change Biol. 15, 808-824.

Brockett, B.F.T., Prescott, C.E., Grayston, S.J., 2012. Soil moisture is the major factor influencing microbial community structure and enzyme activities across seven biogeoclimatic zones in western Canada. Soil Biol. Biochem. 44, 9-20.

364 Bundt, M., Widmer, F., Pesaro, M., Zejer, J., Blaser, P., 2001. Preferential flow paths: biological 'hot spots' in soils. Soil Biol. Biochem. 33, 729-738. 
Carson, J.K., Gonzalez-Quiñones, V., Murphy, D.V., Hinz, C., Shaw, J.A., Gleeson, D.B., 2010. Low pore connectivity increases bacterial diversity in soil. Appl. Environ. Microbiol. 76, 3936-3942.

Castro, H.F., Classen, A.T., Austin, E.E., Norby, R.J., Schadt, C.W., 2010. Soil microbial community responses to multiple experimental climate change drivers. Appl. Environ. Microbiol. 76, 999-1007.

Chemidlin Prévost-Bouré, N., Christen, R., Dequiedt, S., Mougel, C., Lelièvre, M., Jolivet, C., Shahbazkia, H.R., Guillou, L., Arrouays, D., Ranjard, L., 2011. Validation and application of a PCR primer set to quantify fungal communities in the soil environment by Real-Time Quantitative PCR. PloS One 6, e24166.

Chenu, C., Hassink, J., Bloem, J., 2001. Short-term changes in the spatial distribution of microorganisms in soil aggregates as affected by glucose addition. Biol. Fert. Soils 34, 349-356.

Comte, J and del Giorgio, P.A., 2011. Composition influences the pathway but not the outcome of the metabolic response of bacterioplankton to resource shifts. Plos One 6, e25266.

Davinic, M., Fultz, L.M., Acosta-Martinez, V., Calderón, F.J., Cox, S.B., Dowd, S.E., Allen, V.G., Zak, J.C., Moore-Kucera, J., 2012. Pyrosequencing and mid-infrared spectroscopy reveal distinct aggregate stratification of soil bacterial communities and organic matter composition. Soil Biol. Biochem. 46, 63-72.

Dequiedt, S., Saby, N.P.A., Lelièvre, M., Jolivet, C., Thioulouse, J., Toutain, B., Arrouays, D., Bispo, A., Lemanceau, P., Ranjard, L., 2011. Biogeographical patterns of soil molecular microbial biomass as influenced by soil characteristics and management. Global Ecol. Biogeogr. 20, 641-652. 
De Vries, F.T., Bååth, E., Kuyper, T.W., Bloem, J., 2009. High turnover of fungal hyphae in incubation experiments. FEMS Microbiol. Ecol. 67, 389-396.

Dolédec, S., Chessel, D., 1987. Rythmes saisonniers et composantes stationnelles en milieu aquatique I- Description d'un plan d'observation complet par projection de variables. Acta Oecol. - Oec. Gen. 8, 3, 403-426.

Fierer, N., Schimel, J.P., Holden, P.A., 2003. Influence of drying-rewetting frequency on soil bacterial community structure. Microb. Ecol. 45, 63-71.

Fischer, T., 2009. Substantial rewetting phenomena on soil respiration can be observed at low water availability. Soil Biol. Biochem. 41, 1577-1579.

Griffiths, R.I., Whiteley, A.S., O’Donnell, A.G., Bailey, M.J., 2003. Physiological and community responses of established grassland bacterial populations to water stress. Appl. Environ. Microbiol. 69, 6961-6968.

IPCC, 2007. Contribution of Working Groups I, II and III to the Fourth Assessment Report of the Intergovernmental Panel on Climate Change Core Writing Team, Pachauri, R.K., Reisinger, A. (Eds.) IPCC, Geneva, Switzerland, 104 pp.

Jones, S.E., Shade, A.L., McMahon, K.D., Kent A.D., 2007. Comparison of primers sets for use in automated ribosomal intergenic spacer analysis of aquatic bacterial communities: an ecological perspective. Appl. Environ. Microbiol. 73, 2659-2662.

Kaisermann, A., Roguet, A., Nunan, N., Maron, P-A., Ostle, N., Lata J-C., 2013. Agricultural management affects the response of soil bacterial community structure and respiration to water-stress. Soil Biol. Biochem. 66, 69-77.

Lennon, J.T., Aanderud, Z.T., Lehmkuhl, B.K., Schoolmaster, D.R., 2012. Mapping the niche space of soil microorganisms using taxonomy and traits. Ecology 93, 1867-1879. 
413 López-Gutiérrez, J.C., Henry, S., Hallet, S., Martin-Laurent, F., Catroux, G., Philippot, L., 414 2004. Quantification of a novel group of nitrate-reducing bacteria in the environment by real-time PCR. J. Microbiol. Meth. 57, 399-407.

Manninen, S., Forss, S., Venn, S., 2010. Management mitigates the impact of urbanization on meadow vegetation. Urban Ecosyst. 13, 461-481.

418 Manzoni, S., Schimel, J., Porporato, A., 2012. Responses of soil microbial communities to water-stress: Results from a meta-analysis. Ecology 93, 930-938.

Marstorp, H., Guan, X., Gong, P., 2000. Relationship between dsDNA, chloroform labile C and ergosterol in soils of different organic matter contents and $\mathrm{pH}$. Soil Biol. Biochem.

Meier, C., Wehrli, B., van der Meer, J.R., 2008. Seasonal fluctuations of bacterial community diversity in agricultural soil and experimental validation by laboratory disturbance experiments. Microb. Ecol. 56, 210-222.

Or, D., Smets, B.F., Wraith, J.M., Dechesne, A., Friedman, S.P., 2007. Physical constraints affecting bacterial habitats and activity in unsaturated porous media - a review. Adv. Water Resour. 30, 1505-1527.

Pascault, N., Cécillon, L., Mathieu, O., Hénault, C., Sarr, A., Lévêque, J., Farcy, P., Ranjard, L., Maron, P.-A., 2010. In situ dynamics of microbial communities during decomposition of wheat, rape, and alfalfa residues. Microbial Ecol. 60, 816-828.

Ranjard, L., Poly, F., Lata, J.C., Mougel, C., Thioulouse, J., Nazaret, S., 2001. Characterization of bacterial and fungal soil communities by automated ribosomal intergenic spacer analysis fingerprints: biological and methodological variability. Appl. Environ. Microbiol. 67, 4479-4487. 
438 Ruamps, L.S., Nunan, N., Chenu, C., 2011. Microbial biogeography at the soil pore scale. $439 \quad$ Soil Biol. Biochem. 43, 280-286.

440 Schimel, J., Balser, T.C., Wallenstein, M., 2007. Microbial stress-response physiology and its 441 implications for ecosystem function. Ecology 88, 1386-1394.

442 Shelford, V.E., 1931. Some concepts of bioecology. Ecology 12, 455-467.

443 Staddon, P.L., Ramsey, C.B., Ostle, N., Ineson, P., Fitter, A.H., 2003. Rapid turnover of hyphae of mycorrhizal fungi determined by AMS microanalysis of ${ }^{14} \mathrm{C}$. Science 300 , $1138-1140$.

Terrat, S., Christen, R., Dequiedt, S., Lelièvre, M., Nowak, V., Regnier, T., Bachar, D., Plassart, P., Wincker, P., Jolivet, C., Bispo, A., Lemanceau, P., Maron, P.A., Mougel, C., Ranjard, L., 2012. Molecular biomass and MetaTaxogenomic assessment of soil microbial communities as influenced by soil DNA extraction procedure. Microbial

Thioulouse, J., Chessel, D., Dolédec, S., Olivier, J.M., 1997. ADE-4: a multivariate analysis and graphical display software. Stat. Comput. 7, 75-83.

Torsvik, V., Øvreås, L., 2002. Microbial diversity and function in soil: from genes to ecosystems. Curr. Opin. Microbiol. 5, 240-245.

Vainio, E.J., Hantula, J., 2000. Direct analysis of wood-inhabiting fungi using denaturing gradient gel electrophoresis of amplified ribosomal DNA. Mycol. Res. 104, 927-936.

Yuste, J.C., Peñuelas, J., Estiarte, M., Garcia-Mas, J., Mattana, S., Ogaya, R., Pujol, M., Sardans, J., 2011. Drought-resistant fungi control soil organic matter decomposition and its response to temperature. Global Change Biol. 17, 1475-1486.

Zumsteg, A., Bååth, E., Stierli, B., Zeyer, J., Frey, B., 2013. Bacterial and fungal community responses to reciprocal soil transfer along a temperature and soil moisture gradient in a glacier forefield. Soil Biol. Biochem. 61, 121-132. 


\section{CAPTIONS}

465

466

Table 1. Summary statistics of pairwise analysis of independent triplicates of

467 bacterial and fungal ARISA profiles for the four treatments High Moisture (HM), Low

468 Moisture (LM) and Fluctuating Moisture at the end of drying periods (FM-l) and two days

469 after the wetting events (FM-h), during the first month of incubation when the moisture fluctuated.

471
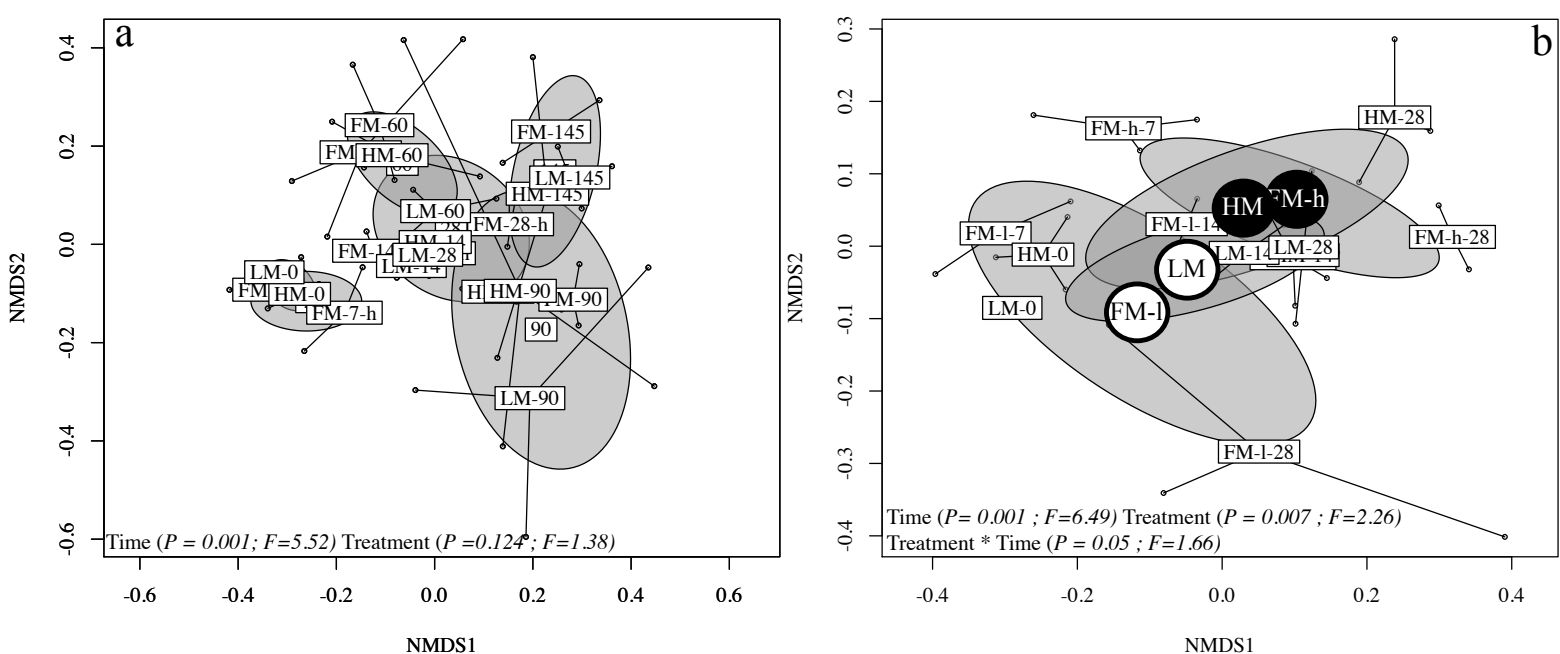

472

473

Fig. 1. Nonmetric multidimensional scaling analysis generated from independent triplicates of bacterial ARISA profiles for the three treatments High Moisture (HM), Low Moisture (LM) and Fluctuating Moisture (FM) at the end of drying periods (FM-l) and two days after the wetting events (FM-h). Figure (a) shows that the genetic structure of bacterial community from day 0 to day 145 (number indicates the sampling day) is grouped by sampling date. Figure (b) focuses on the first month when the moisture fluctuated, for the first (7), second (14) and fourth (28) dry-wet cycles. 

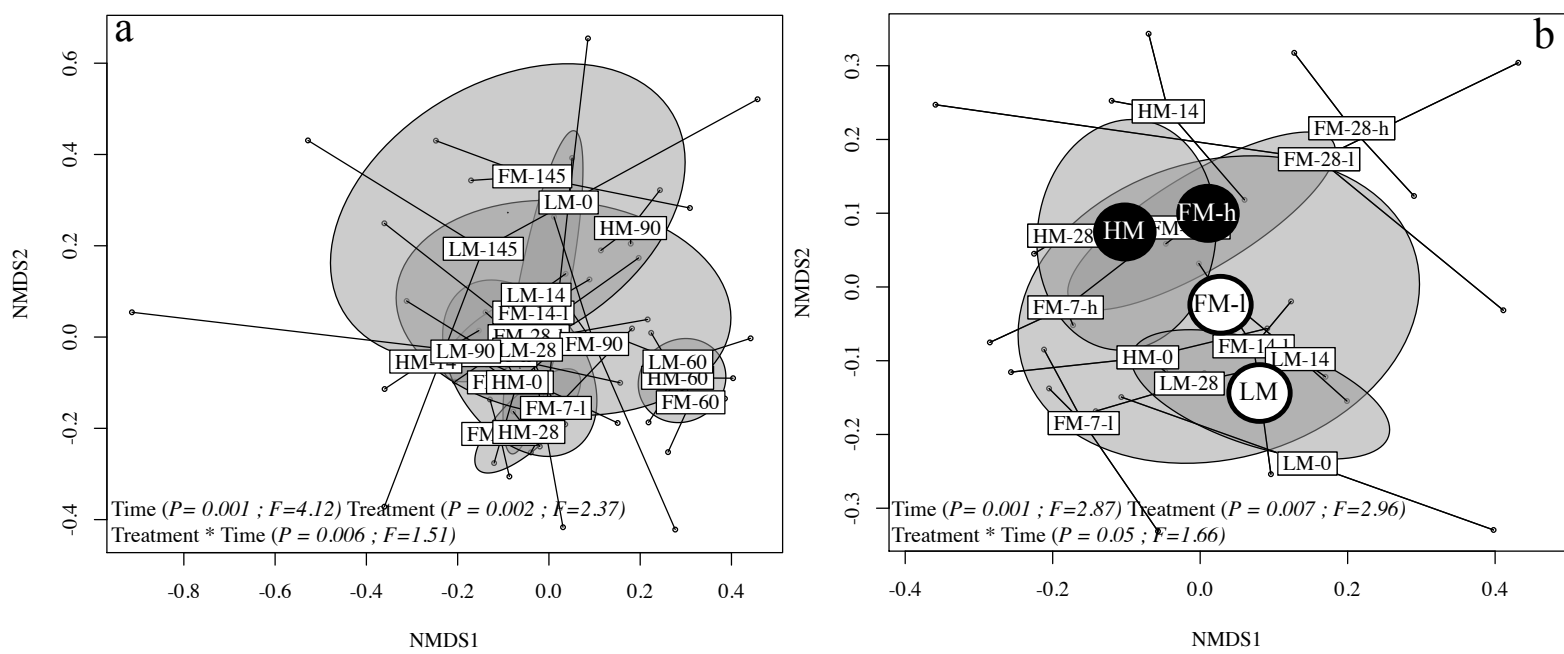

482

483

Fig. 2 Nonmetric multidimensional scaling analysis generated from independent

485 triplicates of fungal ARISA profiles for the three treatments High Moisture (HM), Low

486 Moisture (LM) and Fluctuating Moisture (FM) at the end of drying periods (FM-l) and two

487 days after the wetting events (FM-h). Figure (a) shows the genetic structure of fungal 488 community from day 0 to day 145 (number indicates the sampling day). Figure (b) focuses on

489 the first month when the moisture fluctuated, for the first (7), second (14) and fourth (28) dry490 wet cycles. 

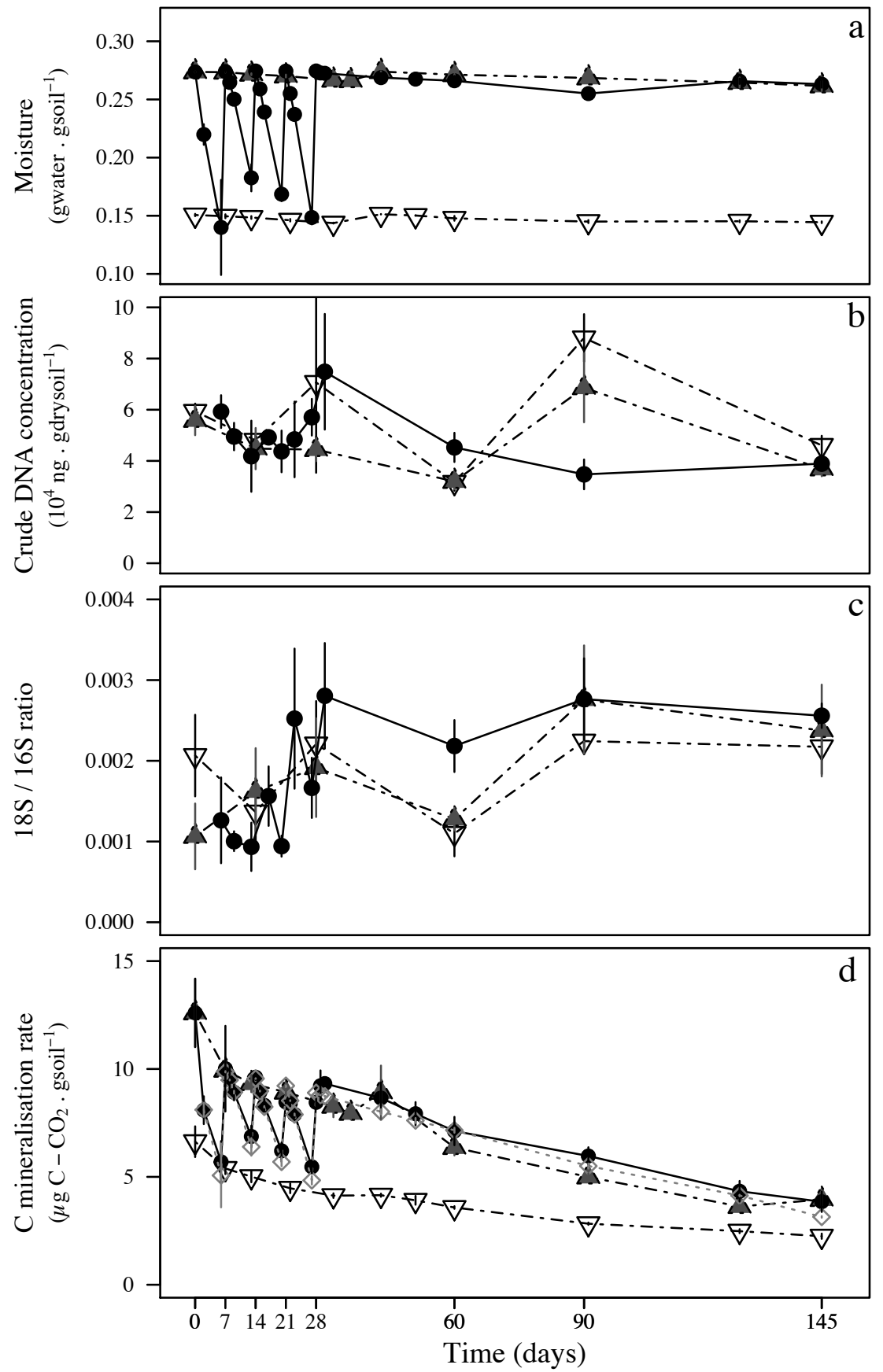

Time (days)

Fig. 3. Moisture (a), molecular microbial biomass (b), fungal:bacterial ratio (c), and

$C$ mineralisation rate (d) for the three treatments High Moisture (HM, black triangles pointing upward), Low Moisture (LM, white triangles pointing downward) and Fluctuating Moisture (FM, black circles). Time 0 is the first day of the first drying period for FM treatment. Grey diamonds represent the $C$ mineralisation calculated with linear model for the FM treatment. Data are mean \pm standard deviation, $n=3$. 


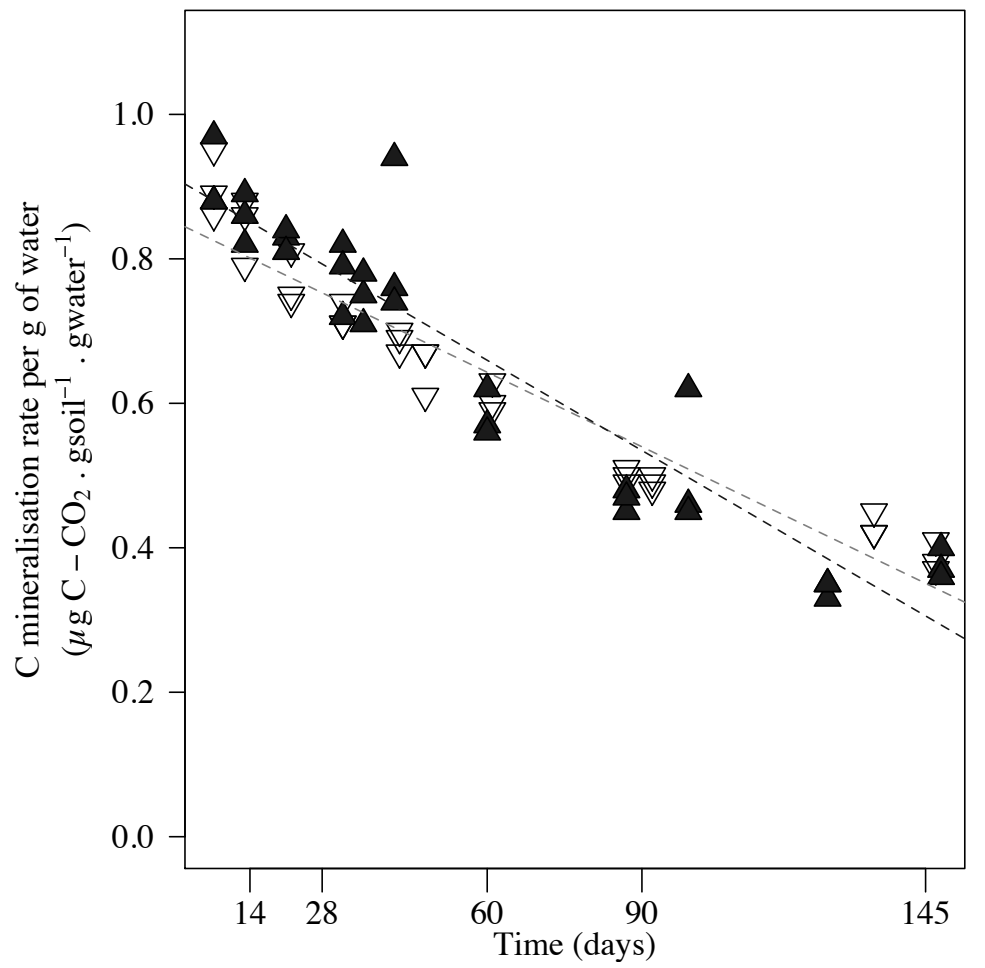

500

$501 \quad$ S1. C mineralisation rate expressed per $g$ of water for Low Moisture (LM, white

502 triangles pointing downward) and High Moisture (HM, black triangles pointing upward)

503 treatments. Time 0 is the first day of the first drying period for FM treatment. The dashed

504 lines are the fitted linear model for each treatment (grey and black for LM and HM,

505 respectively). This figure shows that the activity per water unit decrease as a function of time

506 but is similar at the both water content (treatment effect $P=0.46$, treatment $*$ time effect

$507 P=0.14)$. 